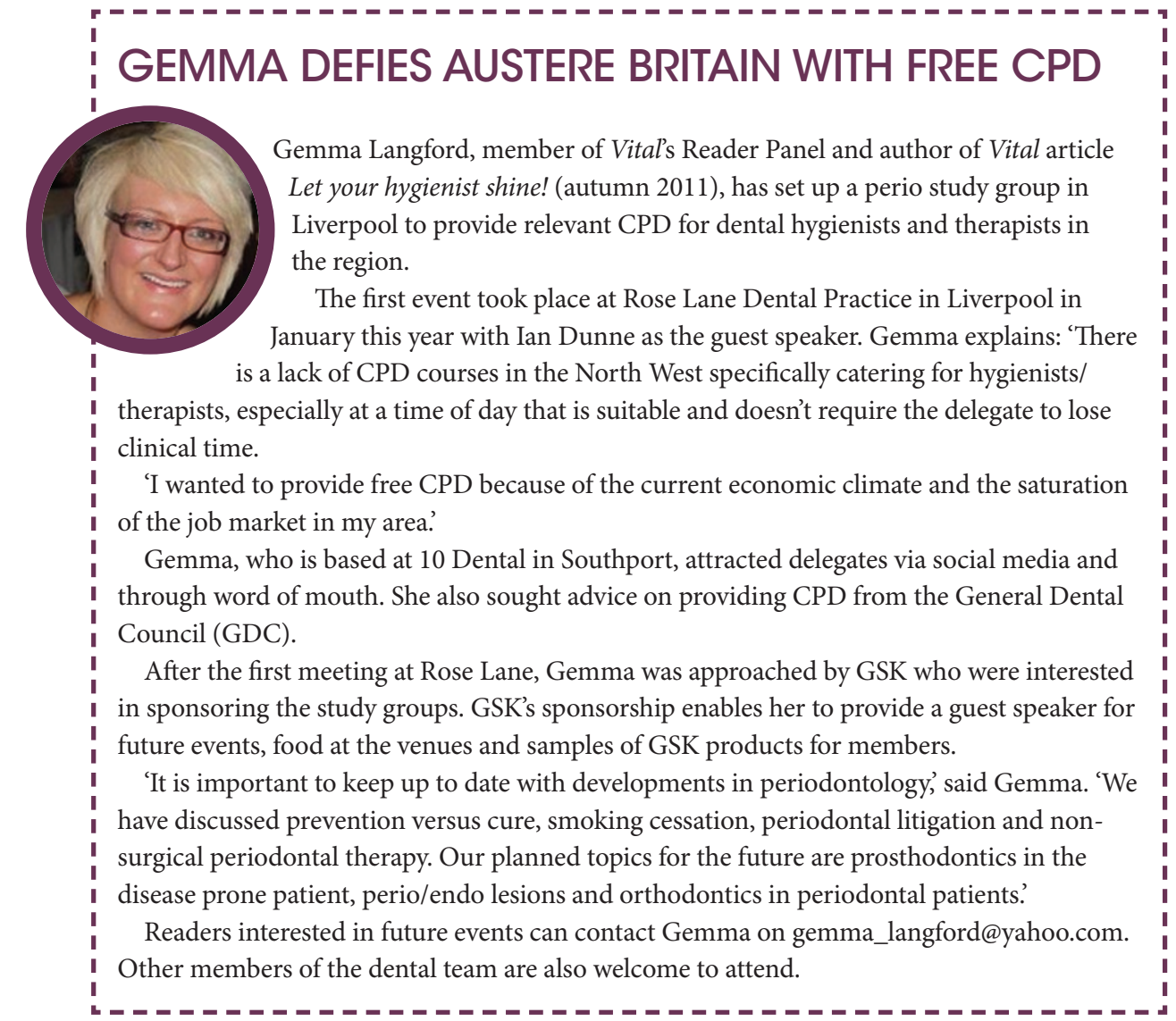

\section{ARF FROZEN FOR THE NEXT YEAR}

The General Dental Council (GDC) has agreed that there will be no increase in the Annual Retention Free (ARF) for the next year for either dentists or dental care professionals (DCPS).

The ARF will remain at £576 for dentists, due by 31 December 2012, and £120 for DCPs, due by 31 July 2013.

Responding to the announcement, Nicola Docherty of the British Association of Dental Nurses (BADN) said that the freeze was 'inadequate' and that it showed that the GDC is 'out of touch with registrants'. The BADN has supplied the GDC with detailed information on dental nurse salaries, showing that $£ 120$ per annum causes considerable financial hardship to dental nurses. It has also requested that the GDC lower the ARF for dental nurses to a fee more in line with salaries and that a special fee is implemented for those working part time.

The GDC was due to meet on 7 November 2012 to consider a proposal for reviewing the ARF policy.

\title{
DENTAL TEAM BRACE THEMSELVES FOR 11 MILE TREK
}

The dental team from South East based Total Orthodontics raised over $£ 5,000$ for The Royal Marsden Cancer Charity by completing an 11 mile trek in Kent.

Total Orthodontics, who have 11 practices in the South East region, embraced the excitement surrounding the Olympics with a sporting theme, with staff dressed as swimmers, show jumpers and even sprinter Usain Bolt.

Marketing Manager Alice Clarke said: 'It was a challenging walk and there were some achy limbs the next day. It was more than worth it though and we were delighted to exceed our $£ 3,000$ fundraising target.'

The Royal Marsden Cancer Charity supports the work of the Royal Marsden Hospital and is at the forefront of cancer research.
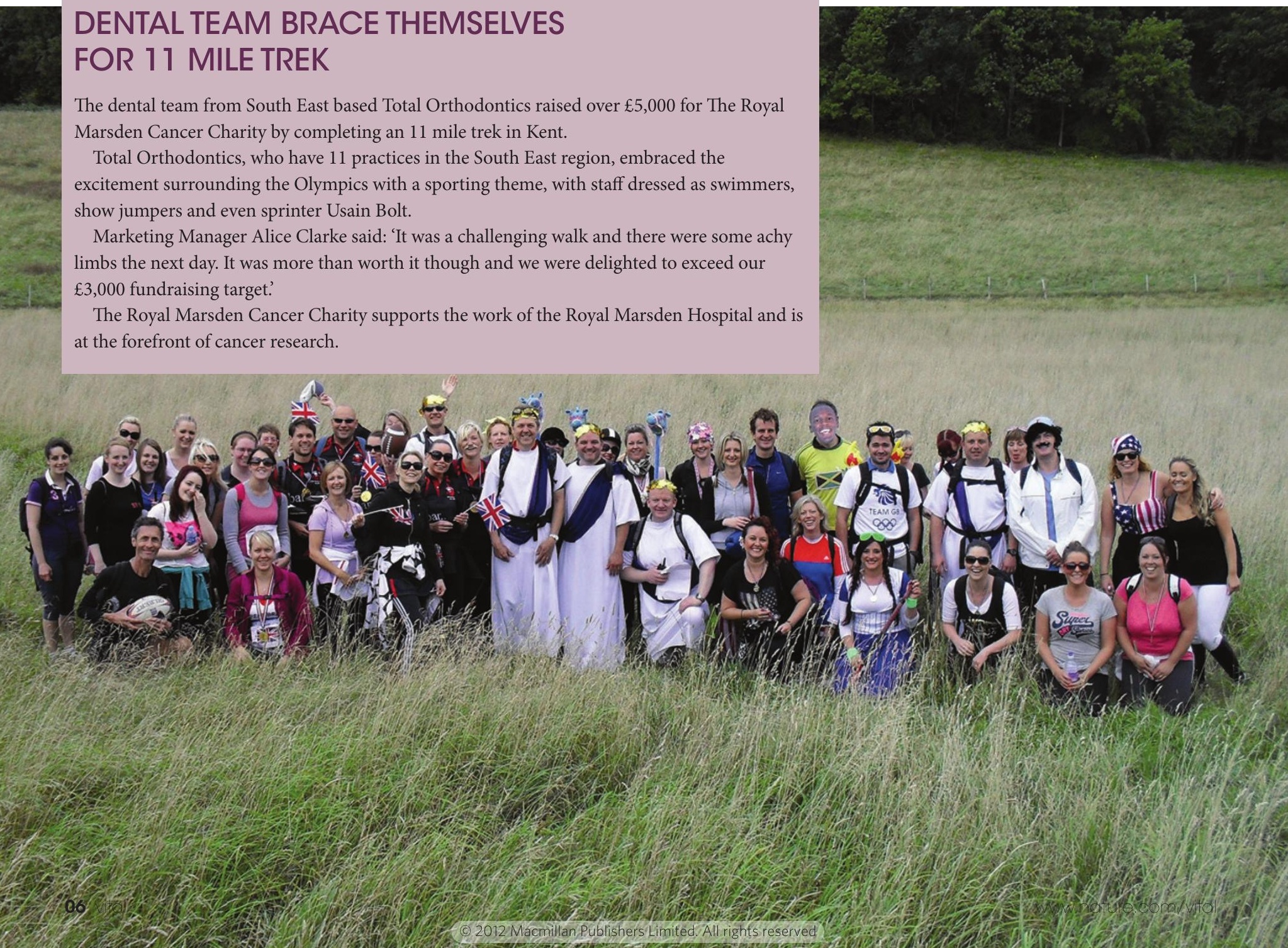